\title{
The Future of Virtual Care for Older Ethnic Adults Beyond the COVID-19 Pandemic
}

Quynh Pham ${ }^{1,2,3^{*}}, \mathrm{PhD}$; Noor El-Dassouki ${ }^{1 *}, \mathrm{BSc}, \mathrm{MSc}$; Raima Lohani ${ }^{1^{*}}, \mathrm{BScN}, \mathrm{MHI}$; Aravinth Jebanesan ${ }^{4}, \mathrm{BSc}$; Karen Young ${ }^{1,2}$, BA

${ }^{1}$ Centre for Global eHealth Innovation, Techna Institute, University Health Network, Toronto, ON, Canada

${ }^{2}$ Institute of Health Policy, Management and Evaluation, Dalla Lana School of Public Health, University of Toronto, Toronto, ON, Canada

${ }^{3}$ Telfer School of Management, University of Ottawa, Ottawa, ON, Canada

${ }^{4}$ Global Health Office, Faculty of Health Science, McMaster University, Hamilton, ON, Canada

*these authors contributed equally

Corresponding Author:

Quynh Pham, PhD

Centre for Global eHealth Innovation

Techna Institute

University Health Network

190 Elizabeth Street

Toronto, ON, M5G 2C4

Canada

Phone: 14163404800 ext 4765

Email: Q.Pham@uhn.ca

\section{Abstract}

The COVID-19 pandemic has fundamentally changed how Canadians access health care. Although it is undeniable that the rapid adoption of virtual care has played a critical role in reducing viral transmission, the gap in equitable access to virtual care remains pervasive for Canada's aging and ethnocultural minority communities. Existing virtual care solutions are designed for the English-speaking, health-literate, and tech-savvy patient population, excluding older ethnic adults who often do not see themselves reflected in these identities. In acknowledging the permanency of virtual care brought on by the pandemic, we have a collective responsibility to co-design new models that serve our older ethnic patients who have been historically marginalized by the status quo. Building on existing foundations of caregiving within ethnocultural minority communities, one viable strategy to realize culturally equitable virtual care may be to engage the highly motivated and skilled family caregivers of older ethnic adults as partners in the technology-mediated management of their chronic disease. The time is now to build a model of shared virtual care that embraces Canada's diverse cultures, while also providing its older ethnic adults with access to health innovations in partnership with equally invested family caregivers who have their health at heart.

(J Med Internet Res 2022;24(1):e29876) doi: 10.2196/29876

\section{KEYWORDS}

virtual care; digital health; health equity; cultural equity; chronic disease; caregivers; ethnocultural minority; older adults; ethnicity; ethnic patients; technology-mediated care; equity; diversity; family

\section{Virtual Care in a Postpandemic World}

The COVID-19 pandemic has fundamentally changed how all Canadians access health care. As initial media coverage showed unsettling scenes of Canada becoming overwhelmed by this new virus, we felt a sense of unease about our own health and the new ways in which we would receive care. With our health care systems stretched and strained to reduce the devastation wreaked by the pandemic, virtual care solutions were rapidly adopted to maintain continuity of care and deliver essential services. Yet in looking deeper at how virtual care became the new standard of care during the pandemic, we know now that this technological transformation did not always benefit those most in need.

Virtual care is defined as "any interaction between patients and/or members of their circle of care, occurring remotely, using any forms of communication or information technologies, with the aim of facilitating or maximizing the quality and effectiveness of patient care" [1]. The first wave of the 
COVID-19 pandemic forced a sharp decline in in-person primary care visits in Canada's most populous province of Ontario as phone and video consultations became the de facto means of accessing care [2]. The second wave of the COVID-19 pandemic saw an even greater shift to virtual care delivery across diverse health care settings such as physiotherapy and postoperative care [3]. Although it is undeniable that virtual care has played a critical role in reducing viral transmission, the future of health care cannot simply be a matter of transitioning current models of care to virtual settings. Sustaining virtual care beyond the pandemic requires us to thoughtfully consider the emerging needs of our society. The Canadian population is growing older, and at the same time, more ethnically diverse. When we look at Canada's growing demographic of aging and ethnically diverse adults, the risk of inequity is stark. First, older adults aged 65 years or older comprise $18 \%$ of the total population and $9 \%$ of the visible minority population $[4,5]$. Second, visible minority older adults are the fastest growing demographic in Canada [6]. Finally, the impact of chronic disease among older adults places a growing burden on our health care system: over $70 \%$ of older adults have been diagnosed with at least one of the 10 most common chronic diseases $[7,8]$. Without a shared strategy to provide equitable access to health care for this emerging population, virtual care runs the risk of exacerbating existing health care inequities for older ethnic adults living with chronic disease $[9,10]$.

In this viewpoint, we refer to the ethnic groups that make up a minority of the Canadian population according to census data and the cultures which characterize them as "ethnocultural minority" communities [11]. Ethnicity comprises the shared aspects of belonging to a group, such as language, ancestry, nationality, and values [12]. The social practices, behavioral norms, and physical expressions of societies — such as traditions, customs, and ideologies-form their culture [13]. Our use of the term "ethnocultural" captures both the shared group aspects and social practices that define ethnicity and culture respectively. In using this terminology, we aim to highlight the ethnic and cultural aspects of caring as factors that influence how patients are able to access virtual care but are often not considered in the design of virtual care platforms.

Early findings on the spread of virtual care during the pandemic in the United States have revealed that older adults, those with limited English proficiency, and those from ethnocultural minority communities have reduced access to virtual care services [10]. Promising work has been done at the intersection of aging, technology, and diversity to improve equity and access to virtual care; solutions include involving patients in technology co-design, increasing access to language interpreters, developing training materials in collaboration with community-based organizations, equipping community centers with the devices and space to receive virtual care, and offering low-tech care options such as telephone visits to improve access [14,15]. However, existing virtual care solutions are often designed for the English-speaking, health-literate, and tech-savvy patient population, and are informed by a biomedical model of health and illness. Older ethnic adults often do not see themselves reflected in these identities and, as such, continue to be excluded from receiving virtual care. Issuing these communities an ultimatum to successfully learn complex technological and self-management behaviors in order to receive care will likely result in even greater isolation and heighten their existing struggles to safely age in place. This feat can be insurmountable in the best of times and is even more overwhelming during a global pandemic when these communities are already experiencing greater health and economic needs [16-19]. Current virtual care models ultimately fail to acknowledge the reality that the same older ethnic adults who are challenged to adopt virtual care are also more likely to have complex health needs and greater difficulties accessing health care [20]. For a population that already experiences deeply rooted health, social, and economic inequities, the inability to access virtual care nearly guarantees that older ethnic adults will struggle to receive any care from increasingly digital-first health systems in a postpandemic world. We believe a new model of virtual care that rejects burdening older ethnic adults with complex requirements in order to access care is desperately needed. One viable strategy to realize culturally equitable virtual care may be to engage the highly motivated and skilled family caregivers of older ethnic adults as partners in the technology-mediated management of their chronic disease.

\section{The Opportunity for Family Caregivers to Become Virtual Care Partners}

Virtual care is here to stay. In acknowledging this new reality, we have a rare opportunity to engage older ethnic adults in virtual care by building on the values that are deeply embedded in their collectivist communities [21]. Despite nuances in how caregiving is defined across cultures, there is a common perception that caring for one's family is a natural and expected part of life [22]. Across many Asian cultures, familial kinship and filial piety represent a deep commitment to caring for aging parents [21]. Although familial kinship places greater value on sharing caregiving responsibilities across family members, filial piety focuses specifically on the parent-child relationship and the practice of caring for one's parents [21,23]. Both familial kinship and filial piety emphasize the value of intergenerational relationships and family-centered approaches to caregiving, which see adult children heavily involved in the role of caring for their ailing parents [23]. We can build on the existing foundations of caregiving within ethnocultural minority communities to establish older ethnic adults and their family caregivers as true partners in virtual care.

Acting on the opportunity presented by this model of care requires us to first understand the intrinsic strengths of family caregiving. Family caregivers provide comprehensive and critical assistance to older ethnic adults navigating the health care system [24]. Although this role can be assumed by partners, siblings, grandchildren, extended family, and friends, the vast majority of caregivers in Ontario are adult children [25]. Through a lifetime of shared experiences, adult children bring an invaluable wealth of knowledge about their parents' health, social, economic, and supportive needs. Their linguistic and cultural relation to their parents affords them some jurisdiction to make joint decisions on how to manage health and illness [26]. These values of familial kinship and filial piety, the cultural 
embeddedness of caregiving, and the ability to inform health care preferences and practices can empower adult children to not only care for their parents, but also to see the value of participating in chronic disease comanagement using virtual care [21-23,27-31]. Many adult child caregivers are also highly educated and have strong digital and health literacy skills [32-34]. Recent census data examining second-generation Chinese and South Asian Canadians-communities that place high value on filial piety-revealed that these groups are generally highly educated and working in advanced information technology occupations [35]. The adult children of older ethnic patients thus present as an extremely valuable resource with skills that will allow them to be the index user of virtual care technologies in the patient-caregiver partnership, thereby removing the burden on their parents to adopt technology [32].

Leveraging this opportunity to comanage chronic diseases through virtual care also requires us to carefully consider the challenges and implications of family caregiving. Caring for a sick family member is psychologically, physically, socially, and financially demanding; experiences of caregiver burnout are unfortunately common [36-39]. The cost of caring for an older family member and witnessing their loss of independence and functional decline can manifest as negative feelings of loss, hostility, and anxiety among family caregivers and strain relationships [40-42]. Caregivers of ethnocultural minority communities also exhibit higher levels of involvement in care activities compared to other ethnic groups, which can further impede their quality of life [43]. In particular, the cultural norms of many ethnocultural minority communities often place the responsibility of caregiving on wives, daughters, and daughters-in-law [23]. Virtual models of shared care should be designed in a way that reduces this gendered burden and removes the need for women to make personal sacrifices to fulfill their filial responsibilities [44].

Significant privacy implications must be considered when operationalizing a model of shared virtual care. Although there are many benefits to sharing personal health information in this context, patients and their caregivers should be informed of the risks of granting shared access. Having caregivers be privy to previously unknown and oftentimes sensitive information can lead to undesired changes to the parent-child relationship and an unintended loss of patient autonomy [45]. For instance, gaining access to personal information can lead caregivers to dominate care decisions and communication with providers, thereby reducing the patient's participation in, and control of, their own care [46]. Establishing routine communication exercises that revisit roles and responsibilities around shared decision-making and care actions, and creating processes that ensure active patient engagement, can help partners to better navigate their shared roles.

\section{Reimagining Virtual Care to Be Culturally Equitable for Older Ethnic Adults}

The future of virtual care for older ethnic adults beyond the COVID-19 pandemic will require a reimagining of the ways in which ethnocultural minority communities access and receive care. Virtual care models that formally engage caregivers have shown promise in improving access to primary and chronic care for older ethnic adults. Latulipe and colleagues $[47,48]$ recently showed that creating caregiver proxy user accounts in patient health portals can allow patients with limited English language proficiency to fully benefit from technologies they would be unable to access otherwise. Piette and colleagues [49-52] have led a decade's worth of formative and definitive trials to study the effectiveness of the CarePartner program and its implementations for heart failure, cancer, diabetes, and mental health. Patients in the CarePartner program complete automated symptom assessments through an interactive voice response (IVR) system and receive tailored health and behavioral advice on how to manage their symptoms. Their caregiver receives a structured report automatically via email with information about the patient's health and what they can do to help. The program has demonstrated significant improvements in symptom management, medication adherence, health service utilization, and emotional coping, with patient-partner dyads reporting improved frequency and quality of communication [51-54]. It is worth noting that the CarePartner Program maintained its effectiveness when deployed in Bolivia to support the dyadic management of diabetes and hypertension [49]. Findings from the randomized trial comparing IVR alone or with automated feedback sent to a caregiver after each IVR assessment showed that caregiver feedback increased engagement with IVR most significantly among patients of Indigenous ethnicity and those with low functional health literacy [55].

Motivated by the successes of dyadic virtual care programs, our team [56] has started to formalize caregiver inclusion in the service design and delivery of our virtual clinics for heart failure and cancer survivorship. Our Medly Clinic [57] supports remote heart failure monitoring [58-61], while our Ned Clinic [62] enables asynchronous prostate cancer survivorship care [63,64]. Both virtual clinics have historically excluded patients who were not comfortable using technology, did not have an email address, and had limited English proficiency; we previously assumed that these factors would challenge patients to use clinic services as intended and derive benefit. The onset of the COVID-19 pandemic created urgency to eliminate barriers to the Medly and Ned clinics as they enabled the provision of services like medication titration and follow-up visits that were paused due to institutional lockdown orders. As a result of increased patient demand for these services, both clinics began enrolling a growing proportion of older ethnic adult patients who were accompanied by their family caregivers and relied on them to adopt the clinic technology. This off-label dyadic approach to onboarding patients who would otherwise not qualify for virtual clinic services brought to light a unique opportunity to formally adapt the clinics for diverse cultural groups. We have since developed Medly Caregiver Live Reports to enable caregivers to view their partner's data generated on the Medly patient app (Figure 1). In parallel to this effort, we drafted new standard operating procedures to formally enroll patient-caregiver dyads into the Ned Clinic and support their shared use of the platform. Our Ned Partners service includes expanded recruitment and onboarding materials, a tips sheet and informal agreement for dyads to align on the challenges of survivorship comanagement, and adapted workflows to 
accommodate changes in their involvement in the clinic and ownership of care tasks over time (Multimedia Appendix 1).

We believe that Canada's virtual care road map requires systemic reform to improve the health and social outcomes of its ethnocultural minority communities. By 2031, 32\% of Canada's population is projected to belong to a visible minority group [65]. As this population ages, they deserve to receive virtual care that they perceive to be acceptable, appropriate, and aligned with their cultural beliefs. We have a collective responsibility to co-design new models of virtual care that reflect these ideals and deliver measurable and sustained impact. Only then can virtual care transition from an exclusive service to an equitable standard that serves those patients who have been historically marginalized by the status quo. The time is now to build a model of shared virtual care that embraces Canada's diverse cultures and provides its older ethnic adults with access to health innovations in partnership with equally invested family caregivers who have their health at heart.

Figure 1. Medly Caregiver Live Report screenshots displaying patient partner health status and data generated on the Medly patient app.
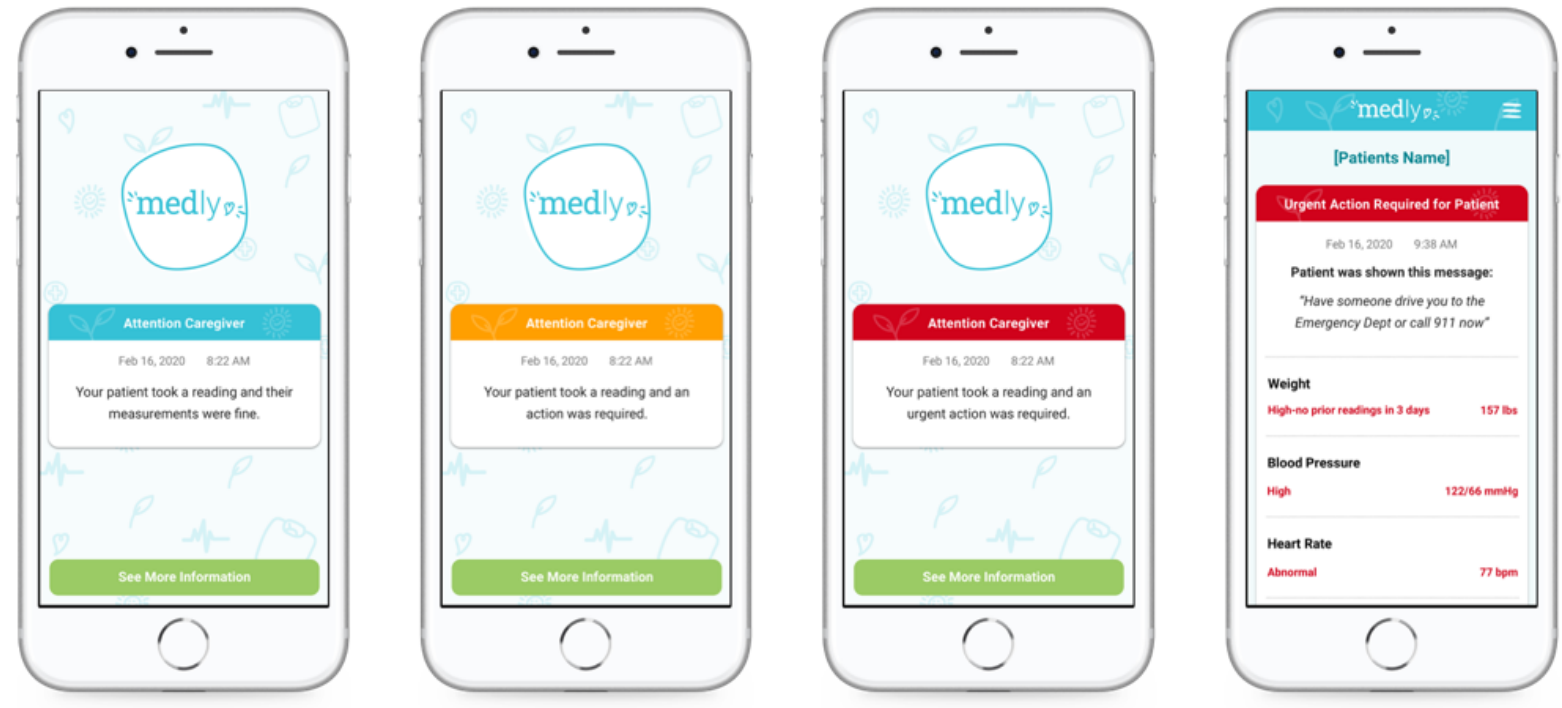

\section{Conflicts of Interest}

QP, NE, RL, and KY are employed by the University Health Network, where the Medly and Ned applications were developed. QP owns intellectual property rights to the Ned application and is entitled to personally benefit from any commercial use of the intellectual property. AJ has no conflicts to declare.

\section{Multimedia Appendix 1}

Ned care partners tip sheet.

[PDF File (Adobe PDF File), 794 KB-Multimedia Appendix 1]

\section{References}

1. Shaw J, Jamieson T, Agarwal P, Griffin B, Wong I, Bhatia RS. Virtual care policy recommendations for patient-centred primary care: findings of a consensus policy dialogue using a nominal group technique. J Telemed Telecare 2018 Oct;24(9):608-615. [doi: 10.1177/1357633X17730444] [Medline: 28945161]

2. Glazier RH, Green ME, Wu FC, Frymire E, Kopp A, Kiran T. Shifts in office and virtual primary care during the early COVID-19 pandemic in Ontario, Canada. CMAJ 2021 Feb 08;193(6):E200-E210 [FREE Full text] [doi:

10.1503/cmaj.202303] [Medline: 33558406]

3. Bhatia RS, Chu C, Pang A, Tadrous M, Stamenova V, Cram P. Virtual care use before and during the COVID-19 pandemic: a repeated cross-sectional study. CMAJ Open 2021 Feb 17;9(1):E107-E114 [FREE Full text] [doi: 10.9778/cmajo.20200311] [Medline: 33597307]

4. Demographic estimates by age and sex, provinces and territories. Statistics Canada. URL: https://www150.statcan.gc.ca/ n1/pub/71-607-x/71-607-x2020018-eng.htm\#htu [accessed 2022-01-02]

5. Visible Minority (15), Generation Status (4), Age (12) and Sex (3) for the Population in Private Households of Canada, Provinces and Territories, Census Metropolitan Areas and Census Agglomerations, 2016 Census - 25\% Sample Data. Statistics Canada. URL: https://www150.statcan.gc.ca/n1/en/catalogue/98-400-X2016190 [accessed 2022-01-02]

6. Immigration and Ethnocultural Diversity in Canada. Statistics Canada. URL: http://www12.statcan.gc.ca/nhs-enm/2011/ as-sa/99-010-x/99-010-x2011001-eng.cfm [accessed 2022-01-02] 
7. Canadian Chronic Disease Indicators (CCDI). Government of Canada. URL: https://health-infobase.canada.ca/ccdi/data-tool/ ?Dom=1 [accessed 2022-01-02]

8. Seniors and the Health Care System: What Is the Impact of Multiple Chronic Conditions?. Canada: Canadian Institute for Health Information; 2021 Jan 01. URL: https://secure.cihi.ca/free_products/air-chronic_disease_aib_en.pdf [accessed 2022-01-03]

9. Crawford A, Serhal E. Digital health equity and COVID-19: the innovation curve cannot reinforce the social gradient of health. J Med Internet Res 2020 Jun 02;22(6):e19361 [FREE Full text] [doi: 10.2196/19361] [Medline: 32452816]

10. Nouri S, Khoong EC, Lyles CR, Karliner L. Addressing equity in telemedicine for chronic disease management during the Covid-19 pandemic. NEJM Catalyst 2020 May 04:1 [FREE Full text]

11. Immigration and ethnocultural diversity: Key results from the 2016 Census.: Statistics Canada; 2017 Oct 25. URL: https:/ /www150.statcan.gc.ca/n1/daily-quotidien/171025/dq171025b-eng.htm?indid=14428-3\&indgeo=0 [accessed 2022-01-02]

12. Proposed Standards for Race-Based and Indigenous Identity Data Collection and Health Reporting in Canada. Ottawa: Canadian Institute for Health Information; 2020. URL: https://www.cihi.ca/sites/default/files/document/ proposed-standard-for-race-based-data-en.pdf [accessed 2022-01-03]

13. Defining culture.: Statistics Canada URL: https://www150.statcan.gc.ca/n1/pub/87-542-x/2011001/section/s3-eng.htm [accessed 2022-01-02]

14. López L, Green AR, Tan-McGrory A, King RS, Betancourt JR. Bridging the digital divide in health care: the role of health information technology in addressing racial and ethnic disparities. The Joint Commission Journal on Quality and Patient Safety 2011 Oct;37(10):437-445. [doi: 10.1016/s1553-7250(11)37055-9]

15. Lyles CR, Sarkar U. Health literacy, vulnerable patients, and health information technology use: where do we go from here? J Gen Intern Med 2015 Mar 15;30(3):271-272 [FREE Full text] [doi: 10.1007/s11606-014-3166-5] [Medline: 25588688]

16. Hou F, Frank K, Schimmele C. Economic impact of COVID-19 among visible minority groups. Statistics Canada. URL: https://tinyurl.com/2p98hsu3 [accessed 2022-01-03]

17. McLaren J. Racial Disparity in COVID-19 Deaths: Seeking Economic Roots with Census Data. Cambridge, MA: National Bureau of Economic Research; 2020 Jun. URL: https://www.nber.org/system/files/working papers/w27407/w27407.pdf [accessed 2022-01-03]

18. Couch KA, Fairlie RW, Xu H. The impacts of COVID-19 on minority unemployment: first evidence from April 2020 CPS microdata. SSRN Journal 2020 May 20:1-42. [doi: 10.2139/ssrn.3604814]

19. Tai D, Shah A, Doubeni C, Sia I, Wieland M. The disproportionate impact of COVID-19 on racial and ethnic minorities in the United States. Clin Infect Dis 2021 Feb 16;72(4):703-706 [FREE Full text] [doi: 10.1093/cid/ciaa815] [Medline: $\underline{32562416]}$

20. Gordon NP, Hornbrook MC. Older adults' readiness to engage with eHealth patient education and self-care resources: a cross-sectional survey. BMC Health Serv Res 2018 Mar 27;18(1):220 [FREE Full text] [doi: 10.1186/s12913-018-2986-0] [Medline: 29587721]

21. Miyawaki CE. A review of ethnicity, culture, and acculturation among Asian caregivers of older adults (2000-2012). Sage Open 2015 Feb 17;5(1):215824401456636 [FREE Full text] [doi: 10.1177/2158244014566365] [Medline: 26229736]

22. Pharr JR, Dodge Francis C, Terry C, Clark MC. Culture, caregiving, and health: exploring the influence of culture on family caregiver experiences. ISRN Public Health 2014 Mar 26;2014:1-8. [doi: 10.1155/2014/689826]

23. Lai DWL. Filial piety, caregiving appraisal, and caregiving burden. Res Aging 2009 Nov 13;32(2):200-223. [doi: $\underline{10.1177 / 0164027509351475}$

24. Lum J. In Focus: Informal Caregiving. Toronto: Ryerson University; 2011. URL: https://www.ryerson.ca/content/dam/ crncc/knowledge/infocus/informalcaregiving/InFocus-InformalCaregiving.pdf [accessed 2022-01-03]

25. Hylmar S. A profile of family caregivers in Ontario. The Change Foundation 2016:1-58.

26. Berry J, Georgas J. An ecocultural perspective on cultural transmission: The family across cultures. In: Cultural Transmission: Psychological, Developmental, Social, and Methodological Aspects. Cambridge, MA: Cambridge University Press; Jun 05, 2012.

27. Jones PS, Winslow BW, Lee JW, Burns M, Zhang XE. Development of a caregiver empowerment model to promote positive outcomes. J Fam Nurs 2011 Feb 22;17(1):11-28. [doi: 10.1177/1074840710394854] [Medline: 21343620]

28. Penrod J, Baney B, Loeb S, McGhan G, Shipley P. The influence of the culture of care on informal caregivers' experiences. ANS Adv Nurs Sci 2012;35:76. [doi: 10.1097/ans.0b013e318244555a]

29. Cheng S, Chan ACM. Filial piety and psychological well-being in well older Chinese. J Gerontol B Psychol Sci Soc Sci 2006 Sep 01;61(5):P262-P269. [doi: 10.1093/geronb/61.5.p262] [Medline: 16960229]

30. Wang J, Liang H, Wu B. Association between filial piety and caregiving burden among Chinese adults' children caregivers. Innovation in Aging 2017;1(suppl_1):1279. [doi: 10.1093/geroni/igx004.4667]

31. Hsueh K, Bachman JA, Richardson LI, Cheng W, Zimmerman RS. Mechanisms through which reciprocal filial values protect wellbeing of Chinese adult-child caregivers in the US. Res Nurs Health 2014 Apr 14;37(2):155-166. [doi: 10.1002/nur.21585] [Medline: 24420507] 
32. Visible Minority (15), Highest Certificate, Diploma or Degree (15), Generation Status (4), Age (9) and Sex (3) for the Population Aged 15 Years and Over in Private Households of Canada, Provinces and Territories and Census Metropolitan Areas, 2016 Census - 25\% Sample Data. Data tables, 2016 Census.: Statistics Canada; 2016. URL: https://tinyurl.com/ 3pz4nks8 [accessed 2022-01-02]

33. Rootman I, Gordon-El-Bihbety D. A Vision for a Health Literate Canada: Report of the Expert Panel on Health Literacy. Canadian Public Health Association. 2008. URL: https://swselfmanagement.ca/uploads/ResourceDocuments/ CPHA\%20(2008)\%20A\%20Vision\%20for\%20a\%20Health\%20Literate\%20Canada.pdf [accessed 2022-01-03]

34. Huynh A, Malli N. Levelling up: the quest for digital literacy. Canada: Brookfield Institute for Innovation \& Entrepreneurship; 2018. URL: https://www.voced.edu.au/content/ngv:80067 [accessed 2022-01-03]

35. Intergenerational Education Mobility and Labour Market Outcomes: Variation Among the Second Generation of Immigrants in Canada.: Statistics Canada URL: https://www150.statcan.gc.ca/n1/pub/11f0019m/11f0019m2019006-eng.htm [accessed 2021-03-12]

36. Adelman RD, Tmanova LL, Delgado D, Dion S, Lachs MS. Caregiver burden: a clinical review. JAMA 2014 Mar 12;311(10):1052-1060. [doi: 10.1001/jama.2014.304] [Medline: 24618967]

37. Gérain P, Zech E. Informal caregiver burnout? Development of a theoretical framework to understand the impact of caregiving. Front Psychol 2019 Jul 31;10:1748 [FREE Full text] [doi: 10.3389/fpsyg.2019.01748] [Medline: 31428015$]$

38. Bastawrous M. Caregiver burden--a critical discussion. Int J Nurs Stud 2013 Mar;50(3):431-441. [doi: 10.1016/j.ijnurstu.2012.10.005] [Medline: 23131724]

39. National Academies of Sciences, Engineering, and Medicine. Economic Impact of Family Caregiving. In: Families Caring for an Aging America. Washington, DC: National Academies Press (US); 2016.

40. Razani J, Kakos B, Orieta-Barbalace C, Wong J, Casas R, Lu P, et al. Predicting caregiver burden from daily functional abilities of patients with mild dementia. J Am Geriatr Soc 2007 Sep;55(9):1415-1420 [FREE Full text] [doi: 10.1111/j.1532-5415.2007.01307.x] [Medline: 17767684]

41. Conway K. The experience of adult children caregiving for aging parents. Home Health Care Management \& Practice 2018 Oct 08;31(2):92-98. [doi: 10.1177/1084822318803559]

42. Bastawrous M, Gignac MA, Kapral MK, Cameron JI. Factors that contribute to adult children caregivers' well-being: a scoping review. Health Soc Care Community 2015 Sep 04;23(5):449-466. [doi: 10.1111/hsc.12144] [Medline: 25472851]

43. Cook SK, Snellings L, Cohen SA. Socioeconomic and demographic factors modify observed relationship between caregiving intensity and three dimensions of quality of life in informal adult children caregivers. Health Qual Life Outcomes 2018 Aug 29;16(1):169 [FREE Full text] [doi: 10.1186/s12955-018-0996-6] [Medline: 30157852]

44. Lai DWL, Luk PKF, Andruske CL. Gender differences in caregiving: a case in Chinese Canadian caregivers. Journal of Women \& Aging 2008 Oct 17;19(3-4):161-178. [doi: 10.1300/j074v19n03 11]

45. Mitnick S, Leffler C, Hood VL, American College of Physicians Ethics, Professionalism and Human Rights Committee. Family caregivers, patients and physicians: ethical guidance to optimize relationships. J Gen Intern Med 2010 Mar 9;25(3):255-260 [FREE Full text] [doi: 10.1007/s11606-009-1206-3] [Medline: 20063128]

46. National Academies of Sciences, Engineering, and Medicine. Family Caregivers' Interactions with Health Care and Long-Term Services and Supports. In: Families Caring for an Aging America. Washington, DC: National Academies Press (US); 2016.

47. Latulipe C, Quandt SA, Melius KA, Bertoni A, Miller DP, Smith D, et al. Insights into older adult patient concerns around the caregiver proxy portal use: qualitative interview study. J Med Internet Res 2018 Nov 02;20(11):e10524 [FREE Full text] [doi: 10.2196/10524] [Medline: $\underline{30389654}$ ]

48. Casillas A, Cemballi AG, Abhat A, Lemberg M, Portz JD, Sadasivaiah S, et al. An untapped potential in primary care: semi-structured interviews with clinicians on how patient portals will work for caregivers in the safety net. J Med Internet Res 2020 Jul 20;22(7):e18466 [FREE Full text] [doi: 10.2196/18466] [Medline: 32706709]

49. Piette JD, Valverde H, Marinec N, Jantz R, Kamis K, de la Vega CL, et al. Establishing an independent mobile health program for chronic disease self-management support in bolivia. Front Public Health 2014 Aug 13;2:95 [FREE Full text] [doi: 10.3389/fpubh.2014.00095] [Medline: 25165687]

50. Silveira MJ, Given CW, Cease KB, Sikorskii A, Given B, Northouse LL, et al. Cancer Carepartners: Improving patients' symptom management by engaging informal caregivers. BMC Palliat Care 2011 Nov 25;10(1):1-11. [doi: $10.1186 / 1472-684 x-10-21]$

51. Bouldin ED, Aikens JE, Piette JD, Trivedi RB. Relationship and communication characteristics associated with agreement between heart failure patients and their Carepartners on patient depressive symptoms. Aging Ment Health 2019 Sep 20;23(9):1122-1129 [FREE Full text] [doi: 10.1080/13607863.2018.1481923] [Medline: 30569750]

52. Piette J, Striplin D, Marinec N, Chen J, Aikens J. A randomized trial of mobile health support for heart failure patients and their informal caregivers: impacts on caregiver-reported outcomes. Medical Care 2015;53:699. [doi: $10.1097 / \mathrm{mlr} .0000000000000378]$

53. Piette J, Striplin D, Aikens J, Lee A, Marinec N, Mansabdar M, et al. Impacts of post-hospitalization accessible health technology and caregiver support on 90-day acute care use and self-care assistance: a randomized clinical trial. Am J Med Qual 2021;36(3):145-155. [doi: 10.1177/1062860620943673] [Medline: 32723072] 
54. Piette JD, Striplin D, Marinec N, Chen J, Trivedi RB, Aron DC, et al. A mobile health intervention supporting heart failure patients and their informal caregivers: a randomized comparative effectiveness trial. J Med Internet Res 2015 Jun 10;17(6):e142 [FREE Full text] [doi: 10.2196/jmir.4550] [Medline: 26063161]

55. Piette JD, Marinec N, Janda K, Morgan E, Schantz K, Yujra ACA, et al. Structured caregiver feedback enhances engagement and impact of mobile health support: a randomized trial in a lower-middle-income country. Telemed J E Health 2016 Apr;22(4):261-268 [FREE Full text] [doi: 10.1089/tmj.2015.0099] [Medline: 26352854]

56. eHealth Innovation. URL: https://ehealthinnovation.org/ [accessed 2021-04-22]

57. Medly. URL: https://medly.ca/ [accessed 2021-04-22]

58. Seto E, Leonard KJ, Cafazzo JA, Barnsley J, Masino C, Ross HJ. Developing healthcare rule-based expert systems: case study of a heart failure telemonitoring system. Int J Med Inform 2012 Aug;81(8):556-565. [doi: 10.1016/j.ijmedinf.2012.03.001] [Medline: 22465288]

59. Ware P, Ross HJ, Cafazzo JA, Boodoo C, Munnery M, Seto E. Outcomes of a heart failure telemonitoring program implemented as the standard of care in an outpatient heart function clinic: pretest-posttest pragmatic study. J Med Internet Res 2020 Feb 08;22(2):e16538 [FREE Full text] [doi: 10.2196/16538] [Medline: 32027309]

60. Ware P, Dorai M, Ross HJ, Cafazzo JA, Laporte A, Boodoo C, et al. Patient adherence to a mobile phone-based heart failure telemonitoring program: a longitudinal mixed-methods study. JMIR mHealth uHealth 2019 Feb 26;7(2):e13259 [FREE Full text] [doi: 10.2196/13259] [Medline: $\underline{30806625}$ ]

61. Ware P, Ross HJ, Cafazzo JA, Laporte A, Gordon K, Seto E. Evaluating the implementation of a mobile phone-based telemonitoring program: longitudinal study guided by the consolidated framework for implementation research. JMIR mHealth uHealth 2018 Jul 31;6(7):e10768 [FREE Full text] [doi: 10.2196/10768] [Medline: $\underline{30064970]}$

62. Ned Clinic. URL: https://nedclinic.ca/ [accessed 2021-04-22]

63. Pham Q, Cafazzo JA, Feifer A. Adoption, acceptability, and effectiveness of a mobile health app for personalized prostate cancer survivorship care: protocol for a realist case study of the ned app. JMIR Res Protoc 2017 Oct 12;6(10):e197 [FREE Full text] [doi: 10.2196/resprot.8051] [Medline: 29025699]

64. Pham Q, Hearn J, Bender JL, Berlin A, Brown I, Bryant-Lukosius D, et al. Virtual care for prostate cancer survivorship: protocol for an evaluation of a nurse-led algorithm-enhanced virtual clinic implemented at five cancer centres across Canada. BMJ Open 2021 Apr 21;11(4):e045806 [FREE Full text] [doi: 10.1136/bmjopen-2020-045806] [Medline: 33883153]

65. Ethnic diversity and immigration.: Statistics Canada URL: https://www150.statcan.gc.ca/n1/pub/11-402-x/2011000/chap/ imm/imm-eng.htm [accessed 2021-02-25]

\section{Abbreviations \\ IVR: interactive voice response}

Edited by A Mavragani; submitted 23.04.21; peer-reviewed by N Gordon, M Wasilewski, E Ray Chaudhuri, W Tang; comments to
author 08.10.21; revised version received 18.10.21; accepted 01.12.21; published 07.01.22
Please cite as:
Pham Q, El-Dassouki N, Lohani R, Jebanesan A, Young K
The Future of Virtual Care for Older Ethnic Adults Beyond the COVID-19 Pandemic
J Med Internet Res 2022;24(1):e29876
URL: $\underline{\text { https://www.jmir.org/2022/1/e29876 }}$
doi: $\underline{10.2196 / 29876}$
PMID:

(CQuynh Pham, Noor El-Dassouki, Raima Lohani, Aravinth Jebanesan, Karen Young. Originally published in the Journal of Medical Internet Research (https://www.jmir.org), 07.01.2022. This is an open-access article distributed under the terms of the Creative Commons Attribution License (https://creativecommons.org/licenses/by/4.0/), which permits unrestricted use, distribution, and reproduction in any medium, provided the original work, first published in the Journal of Medical Internet Research, is properly cited. The complete bibliographic information, a link to the original publication on https://www.jmir.org/, as well as this copyright and license information must be included. 